\title{
Odontogenic Keratocystic Tumor: A Clinical and Histopathologic Retrospective Study Based on the New WHO Classification
}

\author{
Tumor Odontogénico Queratoquístico: Estudio Clínico e Histopatológico \\ Retrospectivo Basado en la Nueva Clasificación de la OMS
}

Taiana Campos Leite*; Valdir Meirelles Jr. ${ }^{* *}$ \& Maria Elisa Rangel Janini*

LEITE, T. C.; MEIRELLES JR., V. \& JANINI, M. E. R. Odontogenic keratocystic tumor: A clinical and histopathologic retrospective study based on the new WHO classification. Int. J. Odontostomat., 5(3):227-234, 2011.

\begin{abstract}
The aim was to review previous cases of Odontogenic Keratocyst or Keratocystic Odontogenic Tumor according to the new WHO classification. We used all cases diagnosed as Odontogenic Keratocyst or Keratocystic Odontogenic Tumor registered in the archives of the Pathologic Anatomy Laboratory of the Department of Pathology and Oral Diagnosis of the School of Dentistry of the Federal University of Rio de Janeiro, Rio de Janeiro, Brazil, which were collected from September, 1983 until September, 2008. The terms "Keratocyst" or "Keratocystic Odontogenic Tumor" were searched for and the following data were collected from the case files: age, sex, location of the lesion(s), and patients' chief complaints. Hematoxilin and Eosin slides were reviewed according to the $2005 \mathrm{WHO}$ criteria. The results found are in accordance with the literature. Due to its benign features, the Orthokeratinized Odontogenic Keratocyst found in our sample had its diagnosis changed to Orthokeratinized Odontogenic Cyst, as recommended by the WHO. Histopathologic exams are required for every bone lesion, in order to establish correct diagnosis. Because of its features, the Keratocystic Odontogenic Tumor must have more aggressive treatment, compared with odontogenic cysts, and long-term follow-up is mandatory.
\end{abstract}

KEY WORDS: odontogenic keratocyst, keratocystic odontogenic tumor, orthokeratinized odontogenic keratocyst, orthokeratinized odontogenic cyst.

\section{INTRODUCTION}

In 2005, the WHO established a new classification to the former known Odontogenic Keratocyst, which is now known as Keratocystic Odontogenic Tumor (KCOT) (Philipsen, 2005). Among the main reasons for this change are its potentially aggressive biological behavior, high recurrence rates, association with the Nevoid Basal Cell Carcinoma Syndrome (NBCCS), the presence of daughter cysts in the capsule, budding of the epithelium basal layer, increase of the mitotic activity, and the influence of genetic alterations, such as mutations of the PTCH gene and loss of heterozygosis of the $9 q 22$ chromosome (Agaram et al., 2004; Madras \& Lapointe, 2008; Vered et al., 2009).

The KCOT is slightly more frequent among men, and may occur at any age range, with peaks between the second and third decades of life. It can be located anywhere in the jaws, most frequently in the mandible posterior region (Ali \& Baughman, 1984; González-Alva et al., 2008; Habibi et al., 2007; Hodgkinson et al., 1978; Chow, 1998; Morgan et al., 2005; Myoung et al., 2001). It may be asymptomatic, or present symptoms, such as expansion of the bones, pain, paresthesia, and purulent discharge (Habibi et al.; Hodgkinson et al.; Chow).

The radiographic presentation varies widely, which makes the diagnosis based exclusively on clinical and radiographic features difficult to determine. KCOTs may present as unilocular images, occasionally in association with roots, simulating other lesions (Ali \& Baughman; Nohl \& Gulabivala, 1996), or as multilocular images, often imitating ameloblastomas, with "soap 
bubble" or "honeycombed" appearance (Omura et al., 1997). These images frequently demonstrate a thin sclerotic border of bone, either well or ill-defined (Brannon, 1976).

KCOTs are histologically composed of a thin squamous epithelium of approximately 5 to 8 cells thick, covered by a thin parakeratinized layer. The basal layer is classically well-defined, with columnar or cuboidal cells in palisade. There may be daughter cysts and epithelial islands in the capsule, and budding of the basal layer (Philipsen; Slootweg, 2006).

The treatment choice must take into account factors such as size and location of the tumor, as well as invasion of the surrounding tissues and previous treatments (Kolokythas et al., 2007). A variety of different treatment modalities have been proposed in the literature, ranging from more conservative options, for instance, marsupialization, to more aggressive ones, such as resection. However, there appears to be a consensus among most authors, according to which an association of techniques seems to be the best choice, for instance, decompression + enucleation, marsupialization + curettage, or enucleation + Carnoy's solution (Blanas et al., 2000; Kolokythas et al.; Marker et al., 1996; Maurette et al., 2006; Morgan et al.).

The purpose of this paper is conducting a retrospective study of past cases of KCOTs of the Department of Pathology and Oral Diagnosis of the School of Dentistry of the Federal University of Rio de Janeiro, through analysis of clinical, epidemiologic, and histopathologic data, from September, 1983, until September, 2008, based on the new WHO classification.

\section{MATERIAL AND METHOD}

All cases diagnosed as Odontogenic Keratocyst or Keratocystic Odontogenic Tumor registered in the archives of the Pathologic Anatomy Laboratory of the
Department of Pathology and Oral Diagnosis of the School of Dentistry of the Federal University of Rio de Janeiro, Rio de Janeiro, Brazil, were collected, from September, 1983 until September, 2008.

This information was collected through research in the register books, where the terms "Keratocyst" or "Keratocystic Odontogenic Tumor" were searched for. The following data were collected from the case files: age, gender, location of the lesion(s), and patients' chief complaints. The absence of any information was considered exclusion criteria for the epidemiologic study.

Hematoxilin and Eosin slides were re-evaluated. All cases had their histopathologic diagnosis reviewed according to the $2005 \mathrm{WHO}$ criteria (Philipsen). These criteria are shown in Table I. The histopathologic evaluation was performed by an author with an Oral Pathology degree.

\section{RESULTS}

Ninety-eight cases of Keratocyst or KCOT were found, in 92 patients. These cases represent $1.3 \%$ of all samples referred for analysis in the Pathology laboratory during the studied period of time. 11 of the 98 cases were excluded from clinical and epidemiologic analysis due to absence of information.

Age and gender distribution. The ages at the moment of diagnosis were taken in consideration. They ranged from 3 to 79 years of age, with a mean of 34.7 years. The peaks were in the $2^{\text {nd }}$ and the $4^{\text {th }}$ decades. The decade distribution is shown in Table II. In two cases, the age was not informed. Regarding gender, there was slight male prevalence, with 48 male cases $(55.2 \%)$, and 39 female cases $(44.8 \%)$, with a $1.23: 1$ ratio.

Tumor location distribution. Among the 87 cases, the location was not informed in one case, and the side was not informed in seven. The tumor location

Table I. Histopathologic criteria for diagnosis of KCOT according to the WHO (Philipsen, 2005).

\begin{tabular}{l} 
Histopatologic criteria \\
\hline Regular parakeratinized stratified squamous epithelium without rete ridges \\
Epithelium 5-8 cell layers thick \\
Well-defined epithelial basal layer with columnar or cuboidal cells frequently containing basophilic nuclei \\
Parakeratotic layers with corrugated surface \\
Loss of characteristic cellular and architectural features in the presence of inflammatory infiltrates
\end{tabular}


distribution is shown in Tables III and IV. In 2 cases $(2.3 \%)$, the tumor affected both maxilla and mandible simultaneously. The others affected the mandible alone most frequently, in 71 cases (81.6\%). Most of these lesions occurred in the body $(n=37$, or $42.5 \%$ of the total). 15 tumors (17.2\%) affected the maxilla, and most of these occurred in the posterior area, including bicuspids and molars ( $n=10$, or $11.5 \%$ of the total).

NBCCS association. In this research, $4(4.6 \%)$ patients suffered from NBCCS, with a total of $6(6.9 \%)$ $\mathrm{KCOTs}$ in these individuals.
Table II. Decade distribution.

\begin{tabular}{lcc}
\hline Decade & Number & Percentage \\
\hline First (0-10 years) & 4 & 4.6 \\
Second (11-20 years) & 18 & 20.7 \\
Third (21-30 years) & 17 & 19.5 \\
Forth (31-40 years) & 18 & 20.7 \\
Fifth (41-50 years) & 11 & 12.6 \\
Sixth (52-60 years) & 9 & 10.3 \\
Seventh (61-70 years) & 6 & 6.9 \\
Eighth (71-80 years) & 2 & 2.3 \\
\hline
\end{tabular}

Table III. Location distribution: Mandible.

\begin{tabular}{lccccccc}
\hline Side & \multicolumn{7}{c}{ Mandible: Areas } \\
\cline { 2 - 7 } & Body & Body+Ramus & Symphysis & Ramus & Angle & Body+Ramus+Condyle & Total \\
\hline Right & 17 & 3 & 0 & 1 & 1 & 1 & 23 \\
Left & 17 & 9 & 0 & 3 & 2 & 0 & 31 \\
Right+Left & 3 & 0 & 0 & 0 & 0 & 0 & 3 \\
Middle & 0 & 0 & 8 & 0 & 0 & 0 & 8 \\
Not & 0 & 3 & 0 & 3 & 0 & 0 & 6 \\
Total & 37 & 15 & 8 & 7 & 3 & 1 & 71 \\
\hline
\end{tabular}

Table IV. Location distribution: Maxilla.

\begin{tabular}{lcccc}
\hline Side & \multicolumn{4}{c}{ Maxilla: Areas } \\
\cline { 2 - 5 } & Posterior (bicuspids and & Anterior (incisives and & Posterior+Anterior & Total \\
\hline Right & 3 & 2 & 0 & 5 \\
Left & 5 & 0 & 2 & 7 \\
Right+Left & 2 & 0 & 0 & 2 \\
Middle & 0 & 1 & 0 & 1 \\
Total & 10 & 3 & 2 & 15 \\
\hline
\end{tabular}

Histopathologic features. Of the 98 cases, $29(29.6 \%)$ slides were not available for analysis.

Keratinization: Of the 69 available cases, in 62 (89.8\%), the epithelium was exclusively parakeratinized (Fig. 1). Six $(8.7 \%)$ epitheliums showed mixed parakeratinization and orthokeratinization. In one $(1.4 \%)$ case, the whole epithelium was orthokeratinized (Fig. 2). This case was reclassified to Orthokeratinized Odontogenic Cyst, based on the new WHO classification.

Epithelial budding of the basal layer: In 17 (24.6\%) samples, there was budding of the epithelial basal layer towards the capsule (Fig. 3).

Epithelial islands and/or cords in the capsule: In
$41(59.4 \%)$ cases, there were epithelial islands and/or cords of odontogenic epithelium in the capsule (Fig. 4).

Dystrophic calcification: Dystrophic calcification was found in the capsule of $28(40.6 \%)$ tumors.

One or more daughter cysts in the capsule: 20 $(29 \%)$ samples had one or more daughter cysts in the tumor's capsule (Fig. 5).

Patient's chief complaints. The patient's chief complaints were registered in their first visit. In some cases, more than one complaint occurred simultaneously. 38 (43.7\%) patients presented swelling of the face, in the area affected by the tumor, $10(11.5 \%)$ reported purulent discharge, and one (1.2\%) presented trismus. These alterations were confirmed after clinical 
examination. In $8(9.2 \%)$ cases, the patient's complaint was pain, and in one $(1.2 \%)$, there was paresthesia of the area affected by the KCOT. $41(47.2 \%)$ cases were asymptomatic, and the lesions were incidentally discovered in radiographic exams (most of which panoramic radiographs), indicated for other reasons, such as orthodontic treatment, or extraction of third molars, and for follow-up of previously NBCCS diagnosed patients.

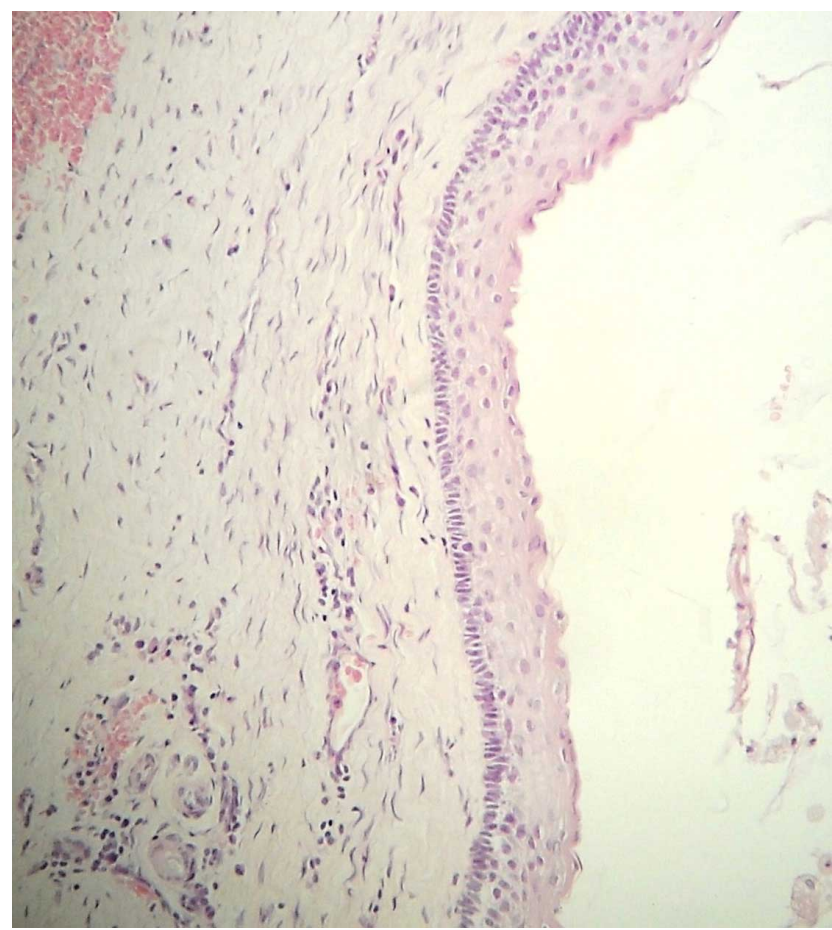

Fig. 1. Parakeratinized epithelium with prominent palisade basal cell layer and corrugated surface. (H\&E staining, original magnification $\times 4$ ).

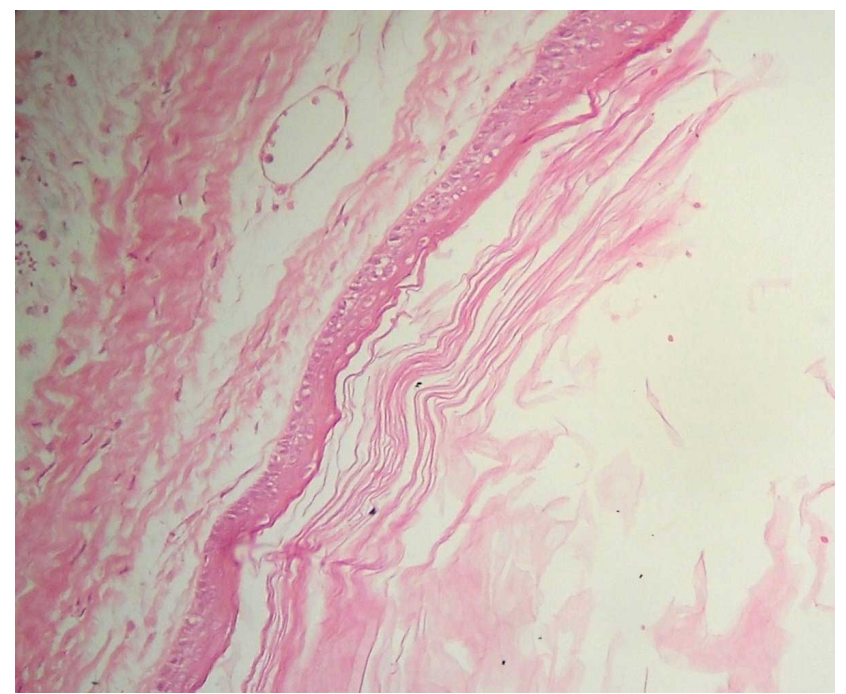

Fig. 2. Orthokeratinized epithelium. (H\&E staining, original magnification $\times 4$ ).

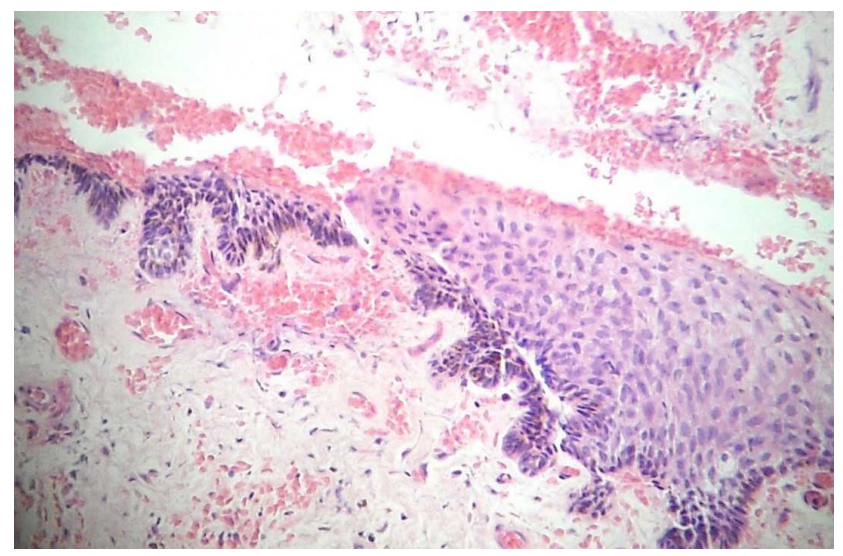

Fig. 3. Epithelial budding of the basal layer. (H\&E staining, original magnification $\times 4$ ).

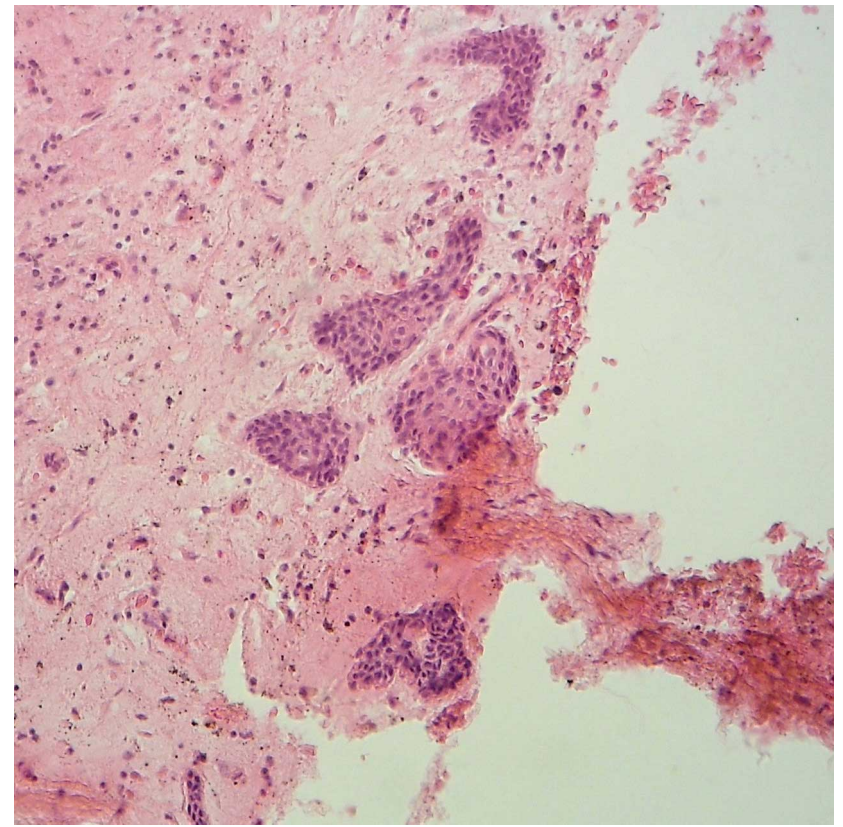

Fig. 4. Islands of odontogenic epithelium within the capsule. (H\&E staining, original magnification $\times 4$ ).

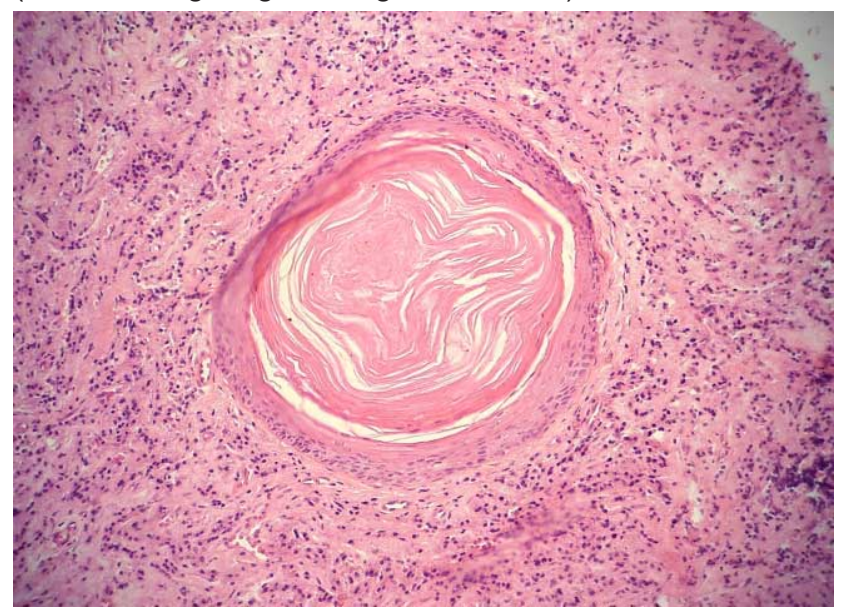

Fig. 5. Prominent daughter cyst in the capsule, containing keratin whorls. (H\&E staining, original magnification $\times 4$ ). 


\section{DISCUSSION}

Regarding gender distribution, our findings are in accordance with those of other studies, which present male predominance (Ali \& Baughman; Brannon; Habibi et al.). The age peaks were $2^{\text {nd }}$ and $4^{\text {th }}$ decades, as was registered by Oda et al. However, most other studies indicate peaks during $2^{\text {nd }}$ and $3^{\text {rd }}$ decades (Brannon; Habibi et al.; Chow).

Most KCOTs occurred in the mandible (81.6\%), which is in agreement with other authors. However, their percentages were slightly lower, ranging from $65.4 \%$ to $76.5 \%$ (Brannon; González-Alva et al.; Myoung et al., 2001; Payne, 1972). The most common area was the body and/or ramus of the mandible, followed by the maxilla's posterior region. Similar results were found in other studies (Myoung et al.; Oda et al., 2000). It is important to note that the tumor tends to grow predominantly in the anterior-posterior direction in the mandible, which allows it to reach large sizes, without causing significant bone expansion. On the other hand, in the maxilla, due to the presence of the maxillary sinus, and to the fact that the bone is thinner, the expansion of the lesion occurs in a spherical manner, which makes it easier to be noticed in an earlier stage (Chow).

After histopathologic analysis, our results regarding epithelial keratinization were similar to those of other authors (Ahlfors et al.; El-Hajj \& Anneroth; González-Alva et al.; Hodgkinson et al.; Myoung et al.). However, higher percentages related to the presence of islands of odontogenic epithelium in the capsule were found $-59.4 \%$ versus $5 \%$ and $23 \%$. (Ahlfors et al., 1984; González-Alva et al.) As to the presence of daughter cysts in the basal layer, our findings were similar to the ones presented by Myoung et al. Finally, regarding the occurrence of budding of the basal layer, our results were similar to Ahlfors et al. It is possible to affirm that these three alterations are significantly present, and therefore represent evidence of the neoplastic nature of the KCOTs (Ahlfors et al.).

In the present study, the Orthokeratinized Odontogenic Keratocyst had its diagnosis changed to Orthokeratinized Odontogenic Cyst (OOC), due to the WHO reclassification (Philipsen). This cyst has very different features compared to the KCOT, not only regarding the keratinization, considering that the OOC is composed exclusively of orthokeratinized epithelium, but particularly because of the biological behavior.
Studies have been performed in order to show the differences between the two entities. An immunohistochemical study revealed a negative reaction to anti-tenascin antibody for $\mathrm{OOC}$ and a positive one for KCOT (da Silva et al., 2002). This is an important factor for the distinction between the two, because tenascin is an adhesion modulating protein, expressed in unstable environments, such as neoplasms and healing areas (da Silva et al.). This study also demonstrated different 10, 13, and 14 cytokeratin expressions between OOC and KCOT. Another immunohistochemical study showed that the $\mathrm{OOC}$ can be originated of gingival and oral mucosa cell rests, while KCOT has its origin from dental lamina cell rests (Koizumi, 2004).

Many patients (47.2\%) exhibited no symptoms or complaints, and had their tumors revealed by radiographic exams ordered for other reasons. This high percentage was similar only to the $49.7 \%$ found by Brannon, while other authors obtained lower, although still significant values, ranging from $5.5 \%$ to 24\% (Ali \& Baughman; Hodgkinson et al.; Chow; Myoung et al.). The absence of symptoms is probably related to the growth pattern of the tumor, which tends to reach a considerably large size before causing expansion of the cortical bone (Hsun-Tau). As in other studies, the most common symptom was swelling (Brannon; Habibi et al.; Chow; Myoung et al.).

The Nevoid Basal Cell Carcinoma Syndrome (NBCCS), also known as Gorlin-Goltz's Syndrome, is an uncommon, hereditary, autosomal dominant disorder (Fitzpatrick \& Thompson, 1982). Recent genetic studies have attributed its occurrence to mutations in the PTCH gene, in the 9q21-23 chromosome (Ljubenovic' et al., 2007). This syndrome is characterized by various alterations, the most significant of which are numerous basal cell carcinomas, multiple KCOTs, and muscle-skeletal malformations, such as bifid ribs and cranial calcifications (Fitzpatrick \& Thompson; MacSweeney et al., 1985). In the present study, $4.6 \%$ of the patients had NBCCS, which is in accordance with data obtained by other authors, whose rates ranged from $1.4 \%$ to 8.8\% (el-Hajj \& Anneroth, 1996; González-Alva et al.; Habibi et al.; Hodgkinson et al.; Chow; Oda et al.).

Numerous clinical, histological, molecular and genetic evidences confirm that the KCOT is indeed a tumor. One of the first studies raising the hypothesis of its neoplastic nature was performed by Ahlfors et al., where aggressive behavior and high recurrence rates 
were mentioned as the main reasons for such classification. These authors drew attention to the invasive features of the epithelium in some of the cases in their histological analysis, and therefore recommended less conservative treatment, in order to avoid recurrence. Studies regarding KCOT demonstrate that there is loss of heterozygosity in some loci of certain chromosomes. These loci are related to DNA unbalance, revealing deletion of tumor suppressor genes (Agaram et al.; Henley et al., 2005). In addition, cell proliferation markers, such as p53, Ki67, and PCNA, as well as certain cytokeratins and suppression of apoptosis-related markers, such as bcl-2 and Bax were also identified (Koizumi; Ogden et al.; Shear, 2002a; Shear, 2002b; Vered et al.) In order to prove the KCOT tissue invasiveness, Heikinheimo et al. (2007) observed reduction in the expression of genes responsible for the formation of extracellular matrix components, and Katase et al. (2007) noticed increase of heparanase (enzyme that is frequently increased in tumors, promoting tissue invasion, angiogenesis, and metastasis) expression in the KCOT epithelial cells.

There are reports of KCOT malignant transformation to squamous cell carcinoma, so followup of patients with KCOT is essential, even after the complete removal of lesion(s) (Falaki et al., 2009; Keszler \& Piloni, 2002; Makowski et al., 2001; Yoshida et al., 1996). Henley et al. performed a molecular study on KCOT and found loss of heterozygosity in some of the loci attributed to squamous cell carcinoma developing, which is a possible explanation for the connection between the two entities. In our sample, there were no cases of malignant transformation.

The complete removal of KCOT is difficult, especially due to the fact that the epithelium is thin and friable, and to the eventual presence of daughter cysts. Therefore, treatment is a challenge, for while there is concern towards avoiding the recurrence rates, there is also an effort towards reducing the surgical morbidity (Morgan et al.). Studies show that simple enucleation is associated with high recurrence rates (Blanas et al.; Morgan et al.), so this technique alone must be avoided. The recurrence rates are significantly reduced when other techniques, such as peripheral ostectomy, the use of Carnoy's solution, or previous decompression, are included (Blanas et al.; Maurette et al.; Morgan et al.). Decompression leads to alterations in the KCOT, the most important of which are thickening of the cystic wall and significant reduction of the cystic cavity, with new bone formation (Clark et al., 2006; Marker et al.). This makes it much easier to remove the whole lesion, consequently reducing the surgical morbidity. This type of strategy may even be used for large and/or multilocular KCOTs. It is effective as treatment modality when combined with enucleation or curettage afterwards, exhibiting low recurrence rates (Kolokythas et al.; Marker et al.; Maurette et al.). It is, however, important to point out that decompression requires patient (or his/her guardian) cooperation, for continuous irrigation of the cavity is needed, during a long period of time - which can be extended to several months. In addition, the patient must return frequently for follow-up (Kolokythas et al.; Maurette et al.). Surgical resection is very aggressive, and, therefore must only be performed in specific situations, for instance in patients who aren't likely to return for follow-up, because the recurrence rates for this type of treatment are close to zero (Blanas et al.). In the present study, the treatment choice for each case wasn't listed, since our institution was only responsible for the diagnosis in the vast majority of cases, and the removal of lesions was performed elsewhere. For this same reason, the recurrence rates were also not informed.

Due to high recurrence rates and aggressive behavior, as well as microscopic, molecular and genetic evidences, proving the neoplastic nature of the KCOT, now recognized by the $\mathrm{WHO}$, treatment for this tumor must be more aggressive than the one performed for cysts, and patient long-term follow-up is mandatory. In addition, it is important to keep in mind that the histopathologic exam must always be performed for lesions in the jaws, in order to allow the best treatment choice.

LEITE, T. C.; MEIRELLES JR., V. \& JANINI, M. E. R. Tumor odontogénico queratoquístico: estudio clínico e histopatológico retrospectivo basado en la nueva clasificación de la OMS. Int. J. Odontostomat., 5(3):227-234, 2011.

RESUMEN: El objetivo fue revisar los casos anteriores de queratoquiste odontogénico ( $Q O)$ o tumor odontogénico queratoquístico (TOQ) de acuerdo con la nueva clasificación de la OMS. Fueron utilizados todos los casos diagnosticados como $Q O$ o TOQ registrados en los archivos del Laboratorio de Anatomía Patológica del Departamento de Patología y Diagnóstico Oral de la Facultad de Odontología de la Universidad Federal de Río de Janeiro, Rio de Janeiro, Brasil, registrados a partir de septiembre de 1983 hasta septiembre del 2008. Los términos "Queratoquiste" o "tumor queratoquistes odontogénicos" se buscaron y los siguientes datos se obtuvieron de los archivos del caso: edad, sexo, localización de la lesión (es), y quejas de los pacientes. Las muestras histológicas de hematoxilina y eosina fueron revisadas de acuerdo a los criterios de la OMS 2005. 
Los resultados encontrados estaban de acuerdo con la literatura. Debido a sus características benignas, el queratoquiste odontogénico ortoqueratinizado encontrado en nuestra muestra había cambiado su diagnóstico de quiste odontogénico ortoqueratinizado, según lo recomendado por la OMS. Los exámenes histopatológicos son necesarios para toda lesión ósea, con el fin de establecer el diagnóstico correcto. Debido a sus características, el TOQ debe tener un tratamiento más agresivo, en comparación con los quistes odontogénicos, donde un seguimiento a mediano y largo plazo es obligatorio.

PALABRAS CLAVE: queratoquiste odontogénico, tumor odontogénico queratoquístico, queratoquiste odontogénico ortoqueratinizado, quiste odontogénico ortoqueratinizado.

\section{REFERENCES}

Agaram, N. P.; Collins, B. M.; Barnes, L.; Lomago, D.; Aldeeb, D.; Swalsky, P.; Finkelstein, S. \& Hunt, J. L. Molecular analysis to demonstrate that odontogenic keratocysts are neoplastic. Arch. Pathol. Lab. Med., 128:313-7, 2004.

Ahlfors, E.; Larsson, A. \& Sjögren, S. The Odontogenic Keratocyst: A benign cystic tumor? J. Oral Maxillofac. Surg., 42:10-9, 1984.

Ali, M. \& Baughman, R. A. Maxillary odontogenic keratocyst: A common and serious clinical misdiagnosis. J. Am. Dent. Assoc., 134:877-83, 2003.

Blanas, N.; Freund, B.; Schwartz, M. \& Furst, I. M. Systematic review of the treatment and prognosis of the odontogenic keratocyst. Oral Surg. Oral Med. Oral Pathol. Oral Radiol. Endod., 90:553-8, 2000.

Brannon, R. B. The odontogenic keratocyst. A clinicopathologic study of 312 cases. Part I. Oral Surg. Oral Med. Oral Pathol., 42:54-72, 1976.

Clark, P.; Marker, P.; Bastian, H. L. \& Krogdahl, A. Expression of p53, Ki-67, and EGFR in odontogenic keratocysts before and after decompression. J. Oral Pathol. Med., 35:568-72, 2006.

Chow, H. T. Odontogenic Keratocyst. A clinical experience in Singapore. Oral Surg. Oral Med. Oral Pathol. Oral Radiol. Endod., 86:573-7, 1998

da Silva, M. J.; de Sousa, S. O.; Corrêa, L.; Carvalhosa, A. A. \& De Araújo, V. C. Immunohistochemical study of the orthokeratinized odontogenic cyst: A comparison with the odontogenic keratocyst. Oral Surg. Oral Med. Oral Pathol. Oral Radiol. Endod., 94:732-7, 2002.

el-Hajj, G. \& Anneroth, G. Odontogenic keratocysts--a retrospective clinical and histologic study. Int. J. Oral Maxillofac. Surg., 25:124-9, 1996.

Falaki, F.; Delavarian, Z.; Salehinejad, J. \& Saghafi, S. Squamous cell carcinoma arising from an odontogenic keratocyst: A case report. Med. Oral Patol. Oral Cir. Bucal, 14:E171-4, 2009.

Fitzpatrick, P. J. \& Thompson, G. A. Gorlin's syndrome, or nevoid basal cell carcinoma syndrome. Can. Med. Assoc. J., 127:465-70, 1982.

González-Alva, P.; Tanaka, A.; Oku, Y.; Yoshizawa, D.; Itoh, S.; Sakashita, H.; Ide, F.; Tajima, Y. \& Kusama, K. Keratocystic odontogenic tumor: a retrospective study of 183 cases. J. Oral Sci., 50:205-12, 2008.

Habibi, A.; Saghravanian, N.; Habibi, M.; Mellati, E. \& Habibi, M. Keratocystic odontogenic tumor: a 10-year retrospective study of 83 cases in an Iranian population. J. Oral Sci., 49:229-35, 2007.

Heikinheimo, K.; Jee, K. J.; Morgan, P. R.; Nagy, B.; Knuutila, S. \& Leivo, I. Genetic changes in sporadic keratocystic odontogenic tumors (odontogenic keratocysts). J. Dent. Res., 86:544-9, 2007.

Henley, J.; Summerlin, D. J.; Tomich, C.; Zhang, S. \& Cheng, L. Molecular evidence supporting the neoplastic nature of odontogenic keratocyst: a laser capture microdissection study of 15 cases. Histopathology, 47:582-6, 2005.

Hodgkinson, D. J.; Woods, J. E.; Dahlin, D. C. \& Tolman, D. E. Keratocysts of the jaw: Clinicopath ologic study of 79 patients. Cancer, 41:803-13, 1978.

Katase, N.; Nagatsuka, H.; Tsujigiwa, H.; Gunduz, M.; Tamamura, R.; Pwint, H. P.; Rivera, R. S.; Nakajima, M.; Naomoto, Y. \& Nagai, N. Analysis of the neoplastic nature and biological potential of sporadic and nevoid basal cell carcinoma syndrome-associated keratocystic odontogenic tumor. J. Oral Pathol. Med., 36:550-4, 2007.

Keszler, A. \& Piloni, M. J. Malignant transformation in odontogenic keratocysts. Case report. Med. Oral, 7:331$5,2002$.

Koizumi, Y. Odontogenic keratocyst, orthokeratinized odontogenic cyst and epidermal cyst: An immunohistochemical study including markers of proliferation, cytokeratin and apoptosis related factors. Int. J. Oral Med. Sci., 2:14-22, 2004.

Kolokythas, A.; Fernandes, R. P.; Pazoki, A. \& Ord, R. A. Odontogenic keratocyst: To decompress or not to decompress? A comparative study of decompression and enucleation versus resection/peripheral ostectomy. J. Oral Maxillofac. Surg., 65:640-4, 2007. 
Ljubenovic', M.; Ljubenovic', D.; Binic', I.; Jovanovic', D. \& Stanojevic', M. Gorlin-Goltz syndrome. Acta Dermatovenerol. Alp. Panonica Adriat., 16:166-9, 2007.

MacSweeney, J. E.; Forbes, A.; Manhir, A. R. \& Lees, W. R. Gorlin's syndrome: case report. J. R. Soc. Med., 78:2535, 1985 .

Madras, J. \& Lapointe, H. Keratocystic odontogenic tumour: reclassification of the odontogenic keratocyst from cyst to tumour. Tex. Dent. J., 125:446-54, 2008.

Makowski, G. J.; McGuff, S. \& Van Sickels, J. E. Squamous Cell Carinoma in a Maxillary Odontogenic Keratocyst. J. Oral Maxillofac. Surg., 59:76-80, 2001.

Marker, P.; Brøndum, N.; Clausen, P. P. \& Bastian, H. L. Treatment of large odontogenic keratocysts by decompression and later cystectomy. Oral Surg. Oral Med. Oral Pathol. Oral Radiol. Endod., 82:122-31, 1996.

Maurette, P. E.; Jorge, J. \& de Moraes, M. Conservative treatment protocol of odontogenic keratocyst: A preliminary study. J. Oral Maxillofac. Surg., 64:379-83, 2006.

Morgan, T. A.; Burton, C. C. \& Qian, F. A retrospective review of treatment of the odontogenic keratocyst. J. Oral Maxillofac. Surg., 63:635-9, 2005.

Myoung, H.; Hong, S. P.; Hong, S. D.; Lee, J. I.; Lim, C. Y.; Choung, P. H.; Lee, J. H.; Choi, J. Y.; Seo, B. M. \& Kim, M. J. Odontogenic keratocyst: Review of 256 cases for recurrence and clinicopathologic parameters. Oral Surg. Oral Med. Oral Pathol. Oral Radiol. Endod., 91:328-33, 2001.

Nohl, F. S. \& Gulabivala, K. Odontogenic keratocyst as periradicular radiolucency in the anterior mandible: Two case reports. Oral Surg. Oral Med. Oral Pathol. Oral Radiol. Endod., 81:103-9, 1996.

Oda, D.; Rivera, V.; Ghanee, N.; Kenny, E. A. \& Dawson, K. H. Odontogenic Keratocyst: The Northwestern USA Experience. J. Contemp. Dent. Pract., 1:60-74, 2000.

Ogden, G. R.; Chisholm, D. M.; Kiddie, R. A. \& Lane, D. P. p53 protein in odontogenic cysts: Increased expression in some odontogenic keratocysts. J. Clin. Pathol., 45:1007-10, 1992.

Omura, S.; Kawabe, R.; Kobayashi, S. \& Mizuki, N. Odontogenic keratocyst appearing as a soap-bubble or honeycomb radiolucency: Report of a case. J. Oral Maxillofac. Surg., 55:185-9, 1997.

Payne, T. F. An analysis of the clinical and histopathologic parameters of the Odontogenic keratocyst. Oral Surg. Oral Med. Oral Pathol., 33:538-46, 1972.
Philipsen, H. P. Keratocystic odontogenic tumor. In: Barnes, L.; Eveson, J. W.; Reichart, P. \& Sidransky, D. (Eds.). World Health Organization classification of tumours: pathology and genetics of head and neck tumours. Lyon, IARC Press, 2005. pp.306-7.

Shear, M. The aggressive nature of the odontogenic keratocyst: is it a benign cystic neoplasm? Part 2. Proliferation and genetic studies. Oral Oncol., 38:32331, 2002a.

Shear, M. The aggressive nature of the odontogenic keratocyst: is it a benign cystic neoplasm? Part 3. Immunocytochemistry of cytokeratin and other epithelial cell markers. Oral Oncol., 38:407-15, 2002b.

Slootweg, P. J. Odontogenic tumors - An update. Curr. Diagn. Pathol., 12:54-65, 2006.

Vered, M.; Peleg, O.; Taicher, S. \& Buchner, A. The immunoprofile of odontogenic keratocyst (keratocystic odontogenic tumor) that includes expression of PTCH, $\mathrm{SMO}, \mathrm{GLI}-1$ and bcl-2 is similar to ameloblastoma but different from odontogenic cysts. J. Oral Pathol. Med., 38:597-604, 2009.

Yoshida, H.; Onizawa, K. \& Yusa, H. Squamous cell carcinoma arising in association with an orthokeratinized odontogenic keratocyst. J. Oral Maxillofac. Surg., 54:64751, 1996.

Correspondence to:

Taiana Campos Leite

Specialist in Oral Medicine and in Operative Dentistry

Dental Clinician

Rua Gustavo Sampaio, 244, bloco B/501

Leme

Rio de Janeiro, RJ

22010-010

BRAZIL

Tel.: (55-21) 8784-1962; (55-21) 2275-7006

Email: taiana_leite@yahoo.com.br

Received: 14-09-2011

Accepted: 12-10-2011 